\title{
Development and validation of the theory of planned behaviour questionnaire on student paramedics' belief of case-based learning
}

Anthony Weber MHIthSc, ICP, MACAP is Deputy Dean (Learning and Teaching) ${ }^{1}$ and Senior Lecturer (Paramedic Science) $)^{2}$; Shannon Delport MTechEMC, BTechEMC, NDPEMC is Senior Lecturer (Paramedic Science) ${ }^{2}$; Gavin Cousens GradDipIntCareParamedicPrac is Lecturer (Paramedic Science) $)^{2}$

Affiliations:

${ }^{1}$ School of Business and Law, Central Queensland University, Rockhampton, Queensland

${ }^{2}$ School of Health, Medical and Applied Science, Central Queensland University, Rockhampton, Queensland

https://doi.org/10.33151/ajp.17.740

\section{Abstract}

\section{Background}

The use of case-based learning (CBL) in the paramedic curriculum has been reported to be a valuable learning tool. Despite this, the use of CBL in distance or online education is not well researched, in particular, identifying the motivation for students to use CBL using a theoretical approach to eliciting and reviewing student paramedics' beliefs.

\section{Aims}

This study aimed to explore the wide range of students' beliefs when it comes to CBL (elicitation of beliefs) and to develop a tool for assessing beliefs in the setting of the theory of planned behaviour (TPB) (development of an assessment instrument).

\section{Methods}

A sequential exploratory study design was used to explore the methodological challenges associated with eliciting beliefs and forming reliable belief scales. The standard components of developing a questionnaire in the context of the theory of planned behaviour were undertaken. Finally, a cross-sectional non-experimental survey design was used to determine the capability of the TPB to predict students' perceptions to CBL in their third year of study.

\section{Results}

In order to learn about the factorial structure of the TPB questionnaire on CBL, a $40-50 \%$ response rate was required; this study had 12 of 25 students (48\%) respond. Using CBL as a focus in paramedic education is subjectively comparable with previous studies in nursing, medicine and allied health professions. It was viewed positively as a linking exercise for consolidation of previously covered work in a paramedic bachelor degree but its true worth not only as a learning tool but for students studying via distance education requires further study and refinement as a model on its own.

\section{Conclusion}

This study was devoted to eliciting students' beliefs about CBL in their education and developing an instrument to assess students' beliefs in the context of the TPB. A pilot study utilising the constructs of the TPB is required to be undertaken in predicting students' behaviour towards CBL within their degree.

\section{Keywords:}

paramedic curriculum; case-based learning; theoretical model; student paramedics; paramedic education 


\section{Introduction}

Paramedic education has transitioned from vocational and employment-based training to tertiary preparation in higher education institutions $(1,2)$. An article by Franklyn-Miller et al describes the evidence behind case-based learning $(\mathrm{CBL})$ in medical education and the erosion of basic sciences leading to recognised knowledge gaps in graduates. The authors highlight CBL as having limited and short-term positive effects in student outcomes and that $\mathrm{CBL}$ inception resulted from the changing landscape of the healthcare paradigm from provider-centric to patient-centric care. This shift saw the early years of medical education evolving to include subjects in arts and humanities, giving the perception that medical program core sciences such as anatomy, physiology and pharmacology were being 'watered down'. The authors went on to suggest a patient-focussed $\mathrm{CBL}$ model as the ideal method for future research in clinical curriculum design (3).

Sir William Osler's (1849-1919) workings in patient-centric healthcare are core to the author's belief that pattern recognition in forming the diagnostic process leads to a differential diagnosis list that directs clinical questioning and investigations. This prompts the clinician to bridge his or her own knowledge gaps as a result of the pattern identification. Sir Osler stated ' ...the best textbook is the patient himself...' to which Franklyn-Miller et al postulate that the use of triggers to narrow down differentials to isolate provisional diagnosis enhances learning and can drive lifelong learning habits (3). Unfortunately, there are no published studies utilising patient focussed $C B L$ and minimal literature describing the relation between $C B L$ in paramedicine and quantitative knowledge benefits. In an attempt to fill knowledge gaps and practice transition, we first need to understand the motivation behind students' intent to consolidate knowledge utilising patient condition specific CBL, which in turn will help improve paramedic graduate transition to practice.

A literature search reveals no current evidence of patientfocussed learning and teaching practices in distance education in paramedicine in Australia. General literature in paramedicine and other health and medical professions suggests the casebased approach for on-campus delivery is effective and satisfying for students but there is no data describing the outcomes of such a learning model (4). Employing similar but modified practices into distance education with a patient focus should be satisfying and pedagogically effective in knowledge application and retention, maintaining motivation for distance students leading to increased student retention for higher education. An appropriate theory to test these hypotheses is required.

More health educational researchers are using the theory of planned behaviour (TPB) to describe a range of behaviours that are not measured under complete volitional control. Empirical research has examined the TPB's effectiveness for behaviours in health education and behaviour of health professionals and students $(5,6)$.

\section{Context for this study}

TPB was developed by Ajzen and colleagues and attempts to predict behaviours over which people do not have complete volitional control (7-9). The theory hypothesises three conceptually independent determinants of behavioural intention (Figure 1). TPB is an extension of the theory of reasoned action (TRA) (7) and similar to the TRA model, the first two determinants of behavioural intention in TPB are attitude toward the behaviour and subjective norm. The third determinant relates to the degree of supposed behavioural control a person has over performing the target behaviour.

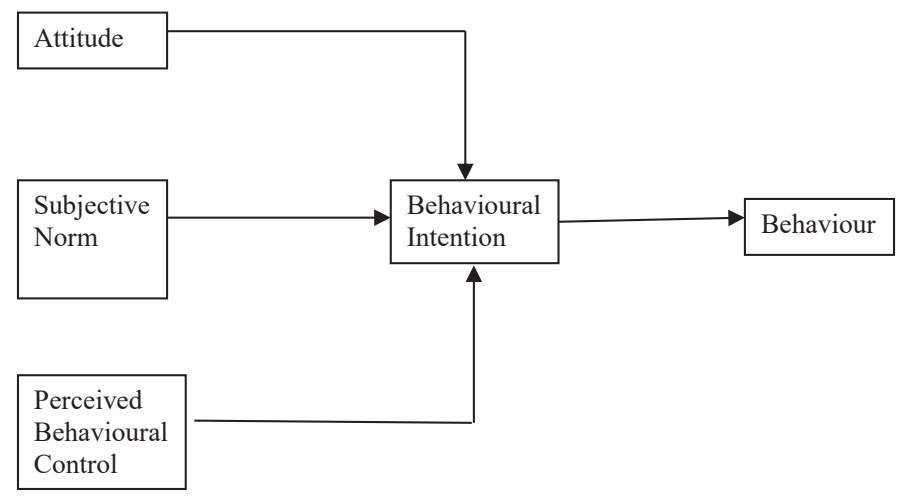

Figure 1. Theory of planned behaviour (8)

In Figure 1, attitude can refer to a person's beliefs around the outcomes of the behaviour (belief strength) shared with an appraisal of the significance of these outcomes (outcome evaluation). By using four to six differentials, attitude can also be directly measured (eg. bad/good) (10). Subjective norm refers to the expectations of significant others' reactions to the performance of the behaviour (normative beliefs) in combination with whether or not the person takes these responses into consideration (incentive to conform). Injunctive social norms have been termed by Nejad and Greenwood as normative beliefs that assess others' approval or disapproval, injunctive social norms (11). The direct measure of perceived control assesses the control individuals think they have in performing the behaviour in question. It is suggested that behavioural intention can be predicted by direct measures of attitude, social norm and perceived control which in turn should predict behaviour (12). TPB can be helpful in designing approaches to assist paramedics to accept change and to help improve their uptake of new clinical guidelines.

Overall the behaviours that are not under complete volitional control can be examined under TPB as it provides a welldefined framework. It has been shown to be a valuable model in predicting intentions from attitude, subjective norm and perceived behavioural control.

It should be addressed that TPB, like the TRA, has a number of limitations that include the following: the model is pertinent only 
to people who are considered 'rational actors'; the model has decreased the predictive ability for cross-sectional studies; badly conducted elicitation interviews may result in inadequate identification of prominent belief items, and the model is intended specifically to predict behavioural intentions which is presumed to lead to actual behaviour (13). As a result, the TPB model may be helpful for predicting student paramedics' beliefs about CBL in preparation for the future careers.

\section{Aims}

The aims of this paper are to explore the wide range of students' beliefs when it comes to CBL (elicitation of beliefs) and to develop a tool for assessing beliefs in the setting of the TPB (development of an assessment instrument).

\section{Methods}

The methodological challenges related to assessing students' beliefs about CBL during the third year of their studies was explored. The aim was to develop dependable belief scales, a methodological innovation in the context of TPB, as single belief items are normally used as predictors for direct measures. The expectancy-value product proved valuable for identifying categories of students' beliefs about CBL. It is predicted that reliable belief scales will emerge, such as control beliefs about external emotional and non-emotional inhibitors and internal facilitators.

\section{The research aims included:}

- What are the extensive range of students' beliefs about CBL (elicitation of beliefs)?

- Information obtained from students will create an instrument for assessing beliefs in the context of TPB (development of an assessment instrument).

- What aspects of the TPB model identify the factors influencing students' perceptions of CBL in third year of studies?

A sequential exploratory study design was used to explore the methodological challenges associated with eliciting beliefs and forming reliable belief scales. The standard components of developing a questionnaire in the context of the TPB were undertaken. Finally, a cross-sectional non-experimental survey design was used to determine the capability of the TPB to predict students' perceptions to CBL in their third year of study. This instrument was initially developed by Ajzen (8) and adapted by Francis et al (16) specifically following the criteria proposed by Ajzen, which in turn guarantees the validity of the instrument's content.

This study investigated student perceptions and beliefs of patient CBL during the third year of study. We aimed to develop reliable questionnaires to be used for eliciting and assessing students' beliefs about CBL in a third-year capstone unit.
A methodological origination in the context of the TPB was used as single belief items as predictors for direct measures are employed through this type of theoretical approach. The students completed a structured online mixed method survey designed to view their perceptions of patient focussed $\mathrm{CBL}$. The construction of the questionnaire is supported by Fishbein and Ajzen and involves four phases: eliciting beliefs from participants; item development of the belief terms; item development; and by the use of expectancy-value products and forming belief scales (14). The reliability and validity of direct TPB measures in assessing students' attitudes towards CBL are to be developed from this elicitation study. In order to test inter-rater (the students) agreement, a test of the proportionate of agreement between the students to further develop questions to be raised as part of the TPB was undertaken through Cronbach's alpha co-efficient measurement. If the responses by students are not reliable or valid at this point, there will be poor prediction of behaviour in a further study using the constructs of the TPB. Cronbach's alpha values greater than $\sim 0.7$ are often taken as representing very good reliability; between 0.5 and 0.7 as good reliability; and equal to or less than 0.5 as moderate reliability (15). SPSS version 24, 2016 was the software used to identify the Kappa co-efficient.

\section{Participants}

All participants were third year Bachelor of Paramedic Science students who voluntarily participated in the study. The study was undertaken over a non-compulsory term of study (term three). A survey was managed electronically by sending a link to the online survey via an email to the student email address. Our study design by using the TPB allows for a moderate effect size of $40-50 \%$ using a regression approach. Therefore with 25 students and having a minimum of 10 for statistical significance we sent email reminders at 14 days and 28 days after the initial contact.

\section{Ethics}

Ethics approval was sought from the Human Research Ethics Committee Research Division and approved - Human Ethics Application outcome - Project Number:/0000021526.

\section{Eliciting beliefs}

As per the recommendation by Fishbein and Ajzen (14), students were provided with open-ended questions that were necessary in eliciting students' beliefs about CBL by identifying the reason students chose paramedicine as a career and their views of $C B L$ throughout the degree. The students were questioned about their previous experiences of CBL related to earlier stages of their degree. Finally, to elicit their belief on external factors affecting their studies, they were asked what made learning through case-based approaches easy or difficult. through case-based approaches easy or difficult.

\section{Item development}

Based on 100\% completion of the open -ended questions, 12 
students' responses were recruited to develop closed-ended items for attitude, subjective norm, perceived behavioural control and behavioural intentions. The questions reflected the words used by students within the elicitation phase of the study. To formulate a questionnaire for students based on responses from the elicitation aspect that was consistent with the TPB constructs, we used a manual created by Francis et al (16).

\section{Results}

After the 28 days, the survey was closed from any further participation. The required sample size is determined by statistical power analysis. This requires the specification of the study design and the expected effect size. For our study, there were 12 students that responded, yielding a $48 \%$ response rate for phase one and two of the study.

\section{Phase 1. Eliciting beliefs by using open-ended questionnaires}

Students' beliefs from the elicitation survey were provided through six open-ended questions focussing on attitude, subjective norm and perceived behavioural control. Question 1: 'please share the major reason why you chose paramedicine as a career' was enquired to see if there is a relationship with behavioural intentions. This first belief question provided varying responses from the challenges of the job to enjoyment helping people and interest in clinical work. This item reflected the thoughts of the students (Table 1) although varying there was a theme across all responses that led to the development of a behavioural intent questionnaire. The final wording of the questionnaire was based on the responses that were described with the best clarity. The behavioural intent questions have a moderate internal consistency, with a Cronbach alpha co-efficient reported of 0.48 . Individual responses statistics revealed mixed results.
In a second step the constructs of the TPB were considered through the open-ended questions asked of the participants. The following six questions were asked: 'When thinking about case-based learning throughout your degree, what challenges do/did you see?' 'What do you think are the positive and negative consequences/outcomes of case-based learning.' 'What teaching experiences from the past influence your thoughts of case-based learning?' 'What do you think are the external factors that would make easier/more difficult for you to learn through case-based learning?' 'What kind of skills or knowledge would make it easier/more difficult for you to learn through case-based learning?' 'Who do you think is likely/unlikely to learn through case-based learning?' We embedded an aspect of the construct of TPB and although the responses addressed the same questions, responses from the students in the elicitation survey differed significantly, presumably as a result of their understanding of CBL. The final questions developed for a study into focussed CBL in third year paramedic students through the application of the TPB was based on the responses that related closely to the students' understanding of $\mathrm{CBL}$.

Table 2 identifies the constructs of the TPB, the questions posed to the students and a summary of answers responded to by the students. Internal consistency and level of agreement of direct measure of attitudes had a very good reliability with a Cronbach alpha co-efficient of 0.77 . Subjective norm's Cronbach's alpha co-efficient was again a good reliability of 0.80 , while perceived behavioural control rated highest with 0.90 .

\section{Phase 2. Item development}

Data from the elicitation survey was used to develop closeended questions for attitude, subjective norm, perceived behavioural control and behavioural intention. The questions for each item was solicited from all the open-ended questions through the elicitation survey.

Table 1. First elicitation question

\begin{tabular}{|l|c|}
\hline \multicolumn{1}{|c|}{ Responses to behavioural intent question } & Cronback alpha \\
\hline $\begin{array}{l}|c| \\
\text { I was interested in medical stuff and interested in helping people as well as liked the idea of working in } \\
\text { the field. So I chose paramedicine }\end{array}$ & 0.52 \\
\hline Improve my employment prospects & 0.13 \\
\hline $\begin{array}{l}\text { Love and work well under pressure. Have a need to make someone's day better. Have ability to adapt } \\
\text { to all sorts of personalities and needs of a person }\end{array}$ & 0.35 \\
\hline $\begin{array}{l}\text { As I find the idea of helping someone on their worst possible day, a very rewarding career choice to } \\
\text { make }\end{array}$ & 0.60 \\
\hline I enjoy clinical work with a lot of unknown. It's an out and about position in the community & 0.45 \\
\hline Challenging, stimulating and rewarding career & 0.32 \\
\hline I want to be a paramedic & 0.22 \\
\hline $\begin{array}{l}\text { I enjoy helping people and have found that pre-hospital emergency care and rescue based roles } \\
\text { interest me a great deal }\end{array}$ & 0.53 \\
\hline Technical, real-time challenges presented in pressure situations & 0.30 \\
\hline
\end{tabular}


Table 2. Elicited questions, theory of planned behaviour constructs and student responses

\begin{tabular}{|c|c|c|}
\hline Elicited question & TPB construct & Student responses (summary) \\
\hline $\begin{array}{l}\text { When thinking about case-based learning } \\
\text { throughout your degree, what challenges do/ } \\
\text { did you see? }\end{array}$ & \multirow[t]{3}{*}{ Attitude } & $\begin{array}{l}\text { Discussing cases online } \\
\text { Very theoretical with differing answers } \\
\text { Lack of case exposure makes it difficult to do } \\
\text { simulations } \\
\text { Actual case exposure makes it easier to do the theory } \\
\text { Lack of knowledge at beginning of the degree } \\
\text { Not enough practice in skills to do case base learning }\end{array}$ \\
\hline \multirow[t]{2}{*}{$\begin{array}{l}\text { What do you think are the positive and } \\
\text { negative consequences/outcomes of case- } \\
\text { based learning? }\end{array}$} & & $\begin{array}{l}\text { Positive: } \\
\text { - prepares you for placement } \\
\text { - excellent review of skills } \\
\text { - draws from actual cases } \\
\text { - puts theory into real world context } \\
\text { - self-directed learning }\end{array}$ \\
\hline & & $\begin{array}{l}\text { Negative: } \\
\text { - present a narrow view } \\
\text { - appears black and white bit isn't } \\
\text { - not having previous exposure makes it hard to do } \\
\text { - dehumanises the patient }\end{array}$ \\
\hline $\begin{array}{l}\text { What teaching experiences from the past } \\
\text { influence your thoughts of case-based } \\
\text { learning? }\end{array}$ & \multirow[t]{3}{*}{ Subjective norm } & $\begin{array}{l}\text { Learning from the past helps shape the future } \\
\text { Case reviews supported learning and completing } \\
\text { assessments } \\
\text { Too much information causes confusion } \\
\text { Provides full clinical picture } \\
\text { Placement was the best teaching experience } \\
\end{array}$ \\
\hline \multirow[t]{2}{*}{$\begin{array}{l}\text { Who do you think is likely/unlikely to learn } \\
\text { through case-based learning? }\end{array}$} & & $\begin{array}{l}\text { Likely: } \\
\text { - students with real life exposure } \\
\text { - every student } \\
\text { - visualise learners }\end{array}$ \\
\hline & & $\begin{array}{l}\text { Unlikely: } \\
\text { - students who don't take the time to learn underlying } \\
\text { - theory } \\
\text { - disengaged students } \\
\text { - people who cannot put clinical picture together }\end{array}$ \\
\hline $\begin{array}{l}\text { What do you think are the external factors } \\
\text { that would make easier/more difficult for you } \\
\text { to learn through case-based learning? }\end{array}$ & \multirow[t]{2}{*}{$\begin{array}{l}\text { Perceived behavioural } \\
\text { control }\end{array}$} & $\begin{array}{l}\text { Many things have such varying degrees of } \\
\text { presentations in the real-world } \\
\text { More live interaction } \\
\text { Distance mode of study } \\
\text { Limited exposure to cases } \\
\text { Being provided varying cases } \\
\text { Having a database of cases }\end{array}$ \\
\hline $\begin{array}{l}\text { What kind of skills or knowledge would make } \\
\text { it easier/more difficult for you to learn through } \\
\text { case-based learning? }\end{array}$ & & $\begin{array}{l}\text { Clinical procedures } \\
\text { Lack of clinical skills practice as a distance student } \\
\text { Access to real cases and watching paramedics in a } \\
\text { case-based scenario } \\
\text { More practice } \\
\text { Tying everything together from year one } \\
\text { More visual examples such as TV or recordings } \\
\text { Prior knowledge of the case }\end{array}$ \\
\hline
\end{tabular}


In response to the first elicitation question asked of students, the following behavioural intent and behavioural belief questions were developed (Table 3).

Table 3. Behavioural intent and behavioural belief questions

\begin{tabular}{|l|}
\hline Behavioural intent \\
\hline I believe case-based learning content is informative \\
\hline I believe case-based learning is a useful tool for learning \\
\hline I believe case-based content is useful \\
\hline Behavioural belief \\
\hline I believe case-based learning content is informative \\
\hline I believe case-based learning is a useful tool for learning \\
\hline I believe case-based content is useful \\
\hline
\end{tabular}

The subsequent six open-ended questions facilitated the following attitude, subjective norm and perceived behavioural control questions (Table 4).

Table 4. Elicited questions, theory of planned behaviour construct

\begin{tabular}{|l|}
\hline Attitude \\
\hline $\begin{array}{l}\text { Has provided me with an effective learning tool to get } \\
\text { through my degree }\end{array}$ \\
\hline $\begin{array}{l}\text { Is a useful learning tool for preparation for the real-world } \\
\text { environment }\end{array}$ \\
\hline Has appropriate learning content to prepare me for practice \\
\hline Subjective norm \\
\hline $\begin{array}{l}\text { People who are important to me think that I should not use } \\
\text { case-based learning to support my progression through my } \\
\text { degree }\end{array}$ \\
\hline $\begin{array}{l}\text { I feel pressure from my peers to use case-based learning } \\
\text { resources to study }\end{array}$ \\
\hline $\begin{array}{l}\text { It is expected of me that I utilise case-based learning } \\
\text { resources to study in my degree }\end{array}$ \\
\hline $\begin{array}{l}\text { I feel pressure from paramedics to use case-based learning } \\
\text { resources (case studies) when on placement }\end{array}$ \\
\hline $\begin{array}{l}\text { Perceived behavioural control. Overall, I feel that case- } \\
\text { based learning has: }\end{array}$ \\
\hline Made me a confident student \\
\hline Provided me confidence on placement \\
\hline Made me feel confident in completing assessment tasks \\
\hline
\end{tabular}

This elicitation study provided the framework for the creation of a questionnaire based on the constructs of the TPB. The response format that will be used for a pilot study into focussed $\mathrm{CBL}$ in third year paramedic students through the application of the TPB is the standard Likert rating scale, which is the standard scale recommended by Ajzen (16). A 7-point Likerttype scale anchored by the use of bipolar adjectives (ie. pairs of opposites) will be used to evaluate student response.

\section{Discussion}

Case-based learning is a student-centred approach which seeks to engage the student into their own learning. The ancient Chinese philosophers write that it's not what the teacher does when learning occurs, it's what the student learns that learning is measured (17). CBL and problem based learning can help clinicians to identify triggers that cause a problem and to identify the problem correctly in order to treat it (18). In a nursing context, graduate nurses of traditional curricula have been known to have difficulty thinking critically, making clinical decisions and unable to recall theory into practice $(19,20)$. Case-based and problem-based learning can focus attention on real-world examples, aligned to the individuals discipline giving context to the material, enhancing motivation and making meaning of the material. This allows the clinician to reflect on the situation and occurrence, code it cognitively for trigger recall to provide a deeper understanding of the science behind the skill and presentation $(17,20)$. Cases need to be authentic and reach across a range of variables and circumstances from the experience of subject matter experts (19).

Yoo and Park's study of CBL found graduates scored higher in both the subjective and objective problem solving skills than their lecture only counterparts (19). When CBL is combined with simulation, it is shown to improve the assessment techniques and process of graduate nurses. It also is intrinsically satisfying to students as it helps to bridge the knowledge gaps in theory and practice (18). Medical students exposed to problem-based learning curricula were found to be superior in determining life threats such as cardiac and respiratory failure and pharmacology applications than lecture-based students (21). For advanced paramedics in Ireland, continuing professional development e-learning case-based scenarios were found to be adaptable, suitable for busy lifestyles and potentially life-long learning habit forming in respondents (22).

Physician certifying and board fellowship examinations found association between failure rates and the lack of basic science knowledge lost after graduation. If the knowledge gained isn't directly and immediately relevant or applied it is lost, including the perception by the learner as to relevance (23). When learning is made relevant and meaningful, deep learning occurs activating a conscientiousness and emotional stability making students willing participants in their learning (24). Casebased learning facilitates the relation of learning to practice by involving higher order thinking and demonstrating the 'big picture' of theory in practice $(25,26)$.

It is interesting to note that the age of 25 is seen as the pivotal point from which child/youth learning shifts to adult learning (27). According to Malcolm Knowles theory of andragogy, adult learners need to know the reason for why they are learning, need practice to experience the learning, learn best with problem solving tools and need to apply the new knowledge 
with immediate effect (28). In this study cohort of respondents, the most negative came from the oldest student $(>35$ years of age) with the younger groups (18-30 years) being the most positive as to the learning model. This information while possibly anomalous, presents as developmental opportunities. It may suggest the learning material was not made as relevant to the student as it could have been, that the student has only surface-learnt the materials due to other confounding factors, the support mechanisms for the older student may not be as robust or the lecturer hasn't adequately connected with the student to help drive motivation.

In patient safety terms, knowing why and when to do a skill or administer a drug is paramount. Being able to relate normal physiology, pathophysiology of disease states, pharmacology and fundamental paramedic skill sets will augment the critical thinking and decision-making pathways of graduate paramedics. It is yet to be determined officially the stakeholder employers' perceptions of paramedic graduate preparation for practice, however, this lands an opportunity to seek clarification for curriculum review, learning and teaching models and future clinical practice. As with many surveys, because of the low response rate (48\%) and limited sample size (12 students), data from the questionnaire should be interpreted with some caution.

\section{Conclusion}

The theory and premise behind $\mathrm{CBL}$ are subjective, with restricted objective data to validate not only that the mode of learning establishes a valuable learning model but if students learning this model via distance education find it more difficult. In this study, using CBL as a focus in paramedic education is subjectively comparable with previous studies in nursing, medicine and allied health professions. It was viewed positively as a linking exercise for consolidation of previously covered work in a paramedic Bachelor degree but its true worth not only as a learning tool but for students studying via distance education requires further study and refinement as a model on its own. This study was devoted to eliciting students' beliefs about CBL in their education and developing an instrument to assess their beliefs in the context of the TPB. The reliability of the sub questions for attitude, subjective norm and perceived behavioural control rated highly. A pilot study utilising the constructs of the TPB is required to be undertaken in predicting students' behaviour towards CBL within their degree.

Numerous possible studies could be developed in the future, such as identifying a larger sample size across a number of universities that allows for confirmatory factor analysis. This approach will further validate the framework and the suggested belief scales and will allow us to explore the relationship between the constructs of the TPB when predicting students' behaviour towards CBL.

\section{Competing interests}

The authors have no competing interests. Each author of this paper has completed the ICMJE conflict of interest statement.

\section{References}

1. O'Brien K, Moore A, Dawson D, Hartley P. An Australian story: paramedic education and practice in transition. Australasian Journal of Paramedicine 2014;11(3).

2. Michau R, Roberts S, Williams B, Boyle M. An investigation of theory-practice gap in undergraduate paramedic education. BMC Med Educ 2009;9:23.

3. Franklyn-Miller A, Falvey E, McCrory P. Patient-based not problem-based learning: an Oslerian approach to clinical skills, looking back to move forward. J Postgrad Med 2009:55:198-203.

4. Williams B. Do undergraduate paramedic students embrace case based learning using a blended teaching approach? A 3 year review. Australian Journal of Educational Technology 2009;25:421-39.

5. Coulson NS, Ferguson MA, Henshaw H, Heffernan E. Applying theories of health behaviour and change to hearing health research: time for a new approach. Int J Audiol 2016;55(Supl 3):S99-104.

6. Weber A, Dwyer T, Mummery K. Morphine administration by paramedics: an application of the theory of planned behaviour. Injury 2012;43:1393-6.

7. Ajzen I, Madden TJ. Prediction of goal-directed behavior: attitudes, intentions, and perceived behavioral control. J Exp Soc Psychol 1986;22:453-74.

8. Ajzen I. The theory of planned behavior organizational behavior and human decision processes. New York: Academic Press. Inc.; 1991. p. 179-211.

9. Ajzen I, Driver B. Application of the theory of planned behavior to leisure choice. J Leis Res 1992;24:207.

10. Conner ME, Sparks P. The theory of planned behaviour and health behaviours. Predicting Health Behaviour 1996:12162.

11. Nejad LW, Greenwood K. Comparison of the health belief model and the theory of planned behviour in the prediction of dieting and fasting behaviour. E-Journal of Applied Psychology Social Section 2005;63-74.

12. Giles MM, Cairns E, Mallet J. An application of the theory of planned behaviour to blood donation: the importance of self-efficacy. Health Educ Res 2004;19:380-91.

13. Madden TJ, Ellen PS, Ajzen I. A comparison of the theory of planned behavior and the theory of reasoned action. Pers Soc Psychology Bulletin 1992;18(1):3-9.

14. Gold GJ. Review of predicting and changing behavior: the reasoned action approach by M. Fishbein and I. Ajzen. New York, NY: Psychology Press, Taylor \& Francis Group, 2010. pp. 518.

15.SPSS survival manual: a step by step guide to data analysis using IBM SPSS. Aust N Z J Public Health 2013;37:597-8. 


\section{References (continued)}

16. Francis J, Eccles MP, Johnston M, et al. Constructing questionnaires based on the theory of planned behaviour: a manual for health services researchers. Newcastle upon Tyne, UK: Centre for Health Services Research, University of Newcastle upon Tyne; 2004.

17. Allchin D. Problem- and case-based learning in science: an introduction to distinctions, values and outcomes. CBE Life Sci Educ 2012;12:364-72.

18. Rauell-Torreda M, Olivet-Pujol J, Romero-Collado A, et al. Case-based learning and simulation: useful tools to enhance nurses education? Nonrandomised controlled trial. J Nurs Scholarsh 2014;47:34-42.

19. Yoo M, Park J. Effect of case-based learning on the development of graduate nurses' problem-solving ability. Nurse Educ Today 2013;34:47-51.

20. Kantar L, Massouh A. Case-based learning: what traditional curricula fail to teach. ibid. 2015;35:e8-14.

21. Radionova Z, Hristova P. Comparative anaylsis of the aquired clinical skills assessment of undergraduate medical students in a problem-based learning and traditional curricula. Perspectives of Innovations, Economics \& Business 2010;6:120-2.
22. Ellis R, Collins N. Scenario-based electronic learning: a viable educational method. Journal of Paramedic Practice 2011:4:96-104.

23. Malau-Aduli B, Lee A, Cooling N, et al. Retention of knowledge and percieved relevance of basic sciences in an integrated case-based learning (CBL) curriculum. BMC Med Educ 2013;13:139.

24. Gray M, Aspland T. Midwifery practice in the university context: perspectives of postgraudate students on the effectiveness of case-based learning in preparation for the workplace. Teach Learn Nurs 2011;6:38-45.

25. Harman T, Bertrand B, Greer A, et al. Case-based learning facilitates critical thinking in undergraduate nutrition education: students describe the big picture. J Acad Nutr Diet 2014;115:378-88.

26.Zhang S, Zheng J, Yang C, et al. Case-based learning in clinical courses in a Chinese college of stomatology. J Dent Educ 2012;76:1389-92.

27. Kelly $\mathrm{C}$, Perkett $\mathrm{D}$. Adult education in the west: origin and definition. 1998. Osaka Gakuin University. Available at: www.osaka-gu.ac.jp/php/kelly/papers/adult-743ed.html

28. Culatta R. Adragogy: Malcolm Knowles. Instructional Design, 2013. Available at: www.instructionaldesign.org/ theories/andragogy/ 